\title{
THE JUNE MEETING IN VICTORIA
}

The six hundred thirty-fifth meeting of the American Mathematical Society was held on Saturday, June 18, 1966 at the University of Victoria in Victoria, British Columbia, in conjunction with meetings of the Pacific Northwest Section of the Mathematical Association of America and the Society for Industrial and Applied Mathematics. There were 181 registrants at this meeting, 105 of whom were members of the Society.

By invitation of the Committee to Select Hour Speakers for Far Western Sectional Meetings, an hour address was given by Professor P. Emery Thomas of the University of California at Berkeley. The title of this address was Vector fields on manifolds. Professor Theodor Ganea introduced Professor Thomas.

There were three sessions for contributed papers with W. R. Ballard, R. E. Odeh, and L. E. Ward, Jr. presiding.

R. S. Pierce

Associate Secretary

Seattle, Washington 